\title{
La paridad en el mundo andino
}

"Un sólo cuerpo: dos energías, cuatro espacios. Según nuestra cosmovisión nosotros somos duales."

\author{
Josef Drexler ${ }^{1,2}$, Rosendo Iván Rojas Reyes ${ }^{3}$, Ángel Polibio Chalán Chalán ${ }^{4}$, David Achig \\ Balarezo ${ }^{5}$ \\ 1 Instituto de Etnología, Universidad de Munich, Oettingenstraße 67, 80538 München, Alemania. \\ 2 Secretaría Nacional para la Educación Superior, la Ciencia, la Tecnología y la Innovación \\ (SENESCYT), Becario PROMETEO, Ecuador. \\ ${ }^{3,5}$ Facultad de Ciencias Médicas, Universidad de Cuenca, Avenida 12 de Abril s/n y El Paraíso, \\ Cuenca, Ecuador. \\ 4 Yachak kichwa, Saraguro-Ilincho. Coordinador de la Carrera de Educación Básica, Universidad \\ Nacional de Loja, Barrio Argelia, Loja.
}

Autor para correspondencia: josef.drexler@gmx.de

Fecha de recepción: 30 de abril de 2015 - Fecha de aceptación: 17 de octubre de 2015

\section{RESUMEN}

El presente artículo aborda el tema de la paridad en el mundo andino. Ofrecemos una discusión en el plan ontológico, cosmológico y socioeconómico desde distintas perspectivas: de la medicina intercultural, de la visión kichwa, de la medicina china y la antropología social y cultural. Las presentes reflexiones critican el paradigma de la dualidad y complementariedad basadas en la discusión de conceptos y prácticas de pueblos indígenas de Ecuador y Colombia, proponiendo modelos teóricos, como la lógica tetraléctica y dialéctica. Se concluye que la paridad es el concepto clave que marca las relaciones sociales, las relaciones entre la sociedad y la naturaleza, que facilita el flujo de la fuerza vital en el pensamiento andino, y que constituye el factor tanto de armonía como de desequilibrio socio-cósmico. El sistema cosmológico de paridades postula la convivencia sociocósmica de solidaridad, como legitimaba en la sociedad incaica tanto el modo de producción tributaria como la redistribución vertical. Teniendo en cuenta los avances posestructuralistas acerca de las ontologías analógicas, concluimos el ensayo con una mirada desde la cosmovisión de la Medicina China y sus fundamentos filosóficos.

Palabras clave: Paridad, dualidad, complementariedad, cosmovisión andina, ontologías analógicas.

\begin{abstract}
The present article discusses the theme of "parity" in the Andean world. The authors offer a discussion of this theme in ontological, cosmological and socioeconomic terms from a variety of perspectives: intercultural medicine, Kichwa cosmovision, traditional Chinese medicine, and social and cultural anthropology. The following considerations are a critical review of the paradigms of duality and complementarity, discussing concepts and practices of indigenous nations in Ecuador and Colombia, and theoretical models, like tetralectical and dialectical logics. The article finds that parity is the key concept that captures Andean social relations, relations between society and nature, the cosmic flow of life forces, and constitutes both socio-cosmic harmony and its imbalances and consequent inversion of space-time. The cosmological system of parity ideologically underpins the normative socio-cosmic co-existence of communal solidarity, while it legitimates the tributarian mode of production and vertical redistribution in Incan society. Considering the advances of post-
\end{abstract}


structuralism on the ontologies of analogism, we conclude our essay with a view of ancestral cosmovision and the ancestral medicine of China.

Keywords: Parity, duality, complementarity, Andean cosmovision, analogical ontologies.

Las consideraciones presentadas en este artículo se deben al encuentro entre la antropología social y cultural y el Equipo de Salud Intercultural de la Facultad de Ciencias Médicas de la Universidad de Cuenca. Durante las largas conversaciones se desarrollaron múltiples diálogos entre los diferentes saberes, afloreciendo un campo interdisciplinario entre la medicina intercultural y la antropología social y cultural, un foro de reflexión, sin llegar a una conclusión colectiva en el sentido de una síntesis dialéctica. Por esta razón hemos decidido presentar nuestras consideraciones respecto a la paridad en el mundo andino en forma de miradas distintas, perspectivas de interpretación alternativas.

\section{UNA MIRADA DE LA PARIDAD DESDE LA PERSPECTIVA DE LA ANTROPOLOGÍA SOCIAL Y CULTURAL}

En su ensayo de interpretar la paridad en el mundo andino, Drexler parte de la frase de un "Sabedor Grande" de la nasa de los Andes colombianos (departamento del Cauca) donde él realizó una investigación de campo entre los años 2002 y 2004. 'Empezando con la "observación participante" (Spradley, 1980), Drexler terminó en la "participación densa" (Spittler, 2001), asistiendo a rituales de "refrescamiento"; por otra parte, las siguientes consideraciones se basan en Drexler's charlas con nasas en el contexto de varias estadías posteriores, entre otros, en su función de asesor internacional de un proyecto de investigación de la Universidad Popayán. ${ }^{2}$

La frase mencionada arriba es de Luis Aureliano Yonda Copaque, un "Sabedor Grande" espiritual (en lenguaje local es Thê'Wala) del pueblo nasa, localizado en el departamento del Cauca, sur-occidente de Colombia. ${ }^{3}$ Según esta cosmovisión, nosotros somos "duales"; en este caso "la "dualidad", una palabra que él deriva-traduce; sin embargo, del Nasa Yuwe peetam, "pareja" (la unión de macho y hembra), respectivamente phtam (la pareja de personas). Luis sigue:

"Por ejemplo, este cuerpo mío, aquí la mitad hacia acá, tiene la energía de la mujer, la izquierda; y de la mitad para acá, tiene la energía del hombre, mi fuerza de hombre. $O$ sea que en un solo cuerpo tengo dos energías. Pero también además tengo, la mitad de acá, por lo del ombligo, son cuatro espacios."

Cuatro espacios en un solo cuerpo, dos femeninos, dos masculinos, y el centro del cuerpo, el ombligo. Y este ombligo conecta al nasa con el universo, con la "madre tierra", mai kiwe, o bien "nuestra tierra" (kwe'sx kiwe) o nasa kiwe, la "tierra de los nasa", que forma apenas una de las tres

\footnotetext{
${ }^{1}$ Siguiendo los estudios de Faust (1994, 1996), Métraux (1949: 563), Roe (1982), Sullivan (1987) y Zerries (1954: 3), entre otros, y teniendo en cuenta sus largos años de (con)vivencias entre diferentes pueblos indígenas de Colombia (los Zenúes de la Costa Caribe, los Nasa de los Andes), Drexler parte de la hipótesis de una base y estructura similar, de "fractales" de las culturas amerindias, especialmente andinas, que permiten el análisis y la comparación, a pesar de las diferencias entre ellas, como por ejemplo de los kichwa y los nasa.

2 El proyecto en cuestión tenía el título: "Recuperación de tecnologías indígenas en la construcción de casas de la Cultura Paez (Nasa)".

3 Luis Aureliano Yonda Copaque es "médico tradicional" del resguardo nasa de Caldono, Cauca; en Nasa Yuwe, él se llama „yu'luuçx“, o sea "hijo del agua”, una denominación que se refiere al origen mítico de los nasa.
} 
casas del cosmos, de la "casa grande", yat wala: como hay la "casa de arriba", êeka kiwe yat,el espacio de las personas espíritu, el origen de la creación-evolución del universo; kwe'sx kiwe yat, o bien nasa kiwe yat, el territorio de aquí, la "Madre Tierra"; y tasxuh kiwe yat, el "espacio de abajo" donde existen otros "hermanos", los "nasa tusxkwe" ("enanos"), y este espacio tiene su propio sol. No obstante, es el ombligo que conecta al nasa con la madre tierra, como es el ombligo del recién nacido que le siembran a la tierra, al territorio. He aquí que se trataría de la estructura tetraléctica del pensamiento andino, siguiendo las propuestas del aymara Yampara Huarachi (2011), mientras que otros intelectuales indianistas como Painiqueo Tramolao (s.f.) de los mapuche, quienes hoy en día quieren matricularse al Tawantinsuyu, hablan de la "dialéctica" (Ngnemapum) "como ley general del universo en su característica única de contradicciones no antagónicas".

Ahora bien, como no nos podemos olvidar del centro del cuerpo humano-cosmos (micro-macro, el pensamiento analógico, del analogismo andino, vea Descola, 2012), nos encontramos frente a una estructura pentaléctica que nos ubica en el Tawantinsuyu del imperio incásico: Chinchaysuyu, Antisuyu, Quillasuyu, Cuntinsuyu, con el centro sagrado de la geografía político-sagrada del universo, el Cuzco (ombligo). Esa misma estructura pentaléctica se encuentra visualizada en las jigras (mochilas) de los nasas, en las figuras romboides: arriba está el Khabu we'sx, el Dios Trueno, el $K p$ 'sx que es el dueño de la vara de mando ( $k h a b u)$ del universo; en la parte izquierda sigue el $A m$ we'sx, el trueno con el hacha; en la parte derecha el Izu we'sx, el trueno con la honda que lanza el relámpago; y en la tierra está el Thê'Wala, el representante del Trueno, como el Trueno es su Dios-EspírituGuardián.
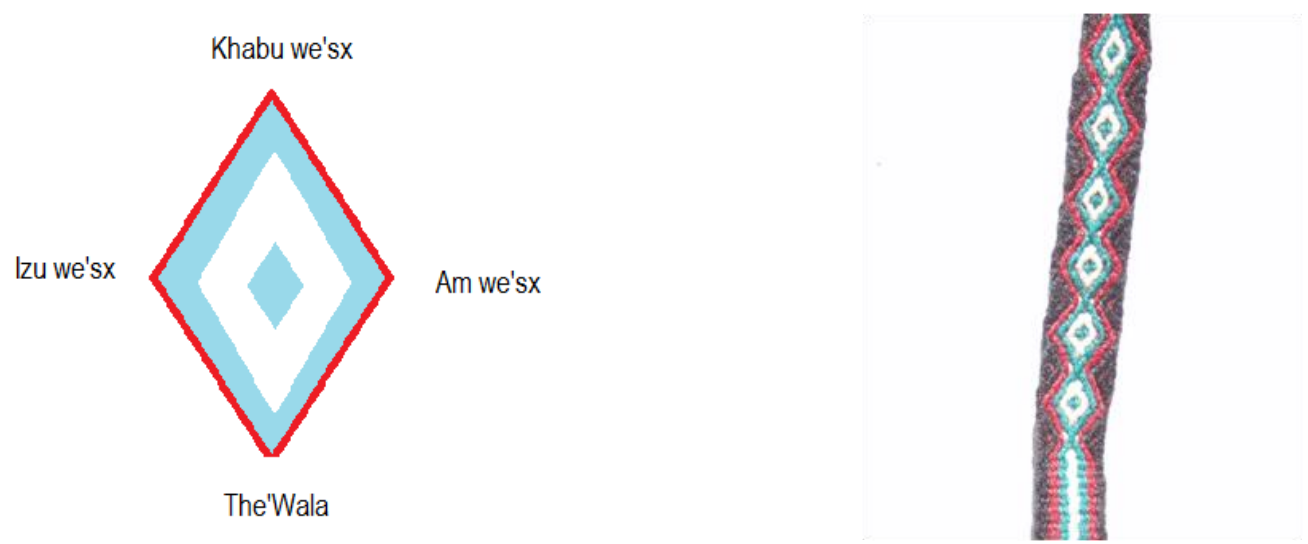

Mochila (kwetiandera) nasa

Figura 1. Las cuatro manifestaciones del Dios-Trueno, como se encuentran en las jigras (vea foto en la derecha) de los nasa (Figura y foto elaborada por Josef Drexler).

Ahora bien, si la cosas fueran tan fáciles. El pensamiento andino fluye, está en permanente circulación, pareciéndose al pensamiento posestructuralista, construyendo, deconstruyendo y reconstruyendo estructuras, conectando y desconectando paridades. Luis Yonda Copaque sigue en sus comentarios:

"Nosotros mismos, los seres humanos, tenemos diferentes guardianes. Por ejemplo, nosotros los hombres, desde que engendramos, desde que quedamos engendrados en el vientre con una vida, ya quedamos con un guardián, una guardiana espiritualmente, que eso está conectado con el cosmos. Por ejemplo, en el caso de los hombres, siempre tenemos guardianes mujeres, o sea una mujer espiritual que usted desde que queda en el óvulo fecundado, ya queda usted con una mujer. En el caso de la mujer, es el hombre espiritualmente. Por eso que en la cosmovisión, en la espiritualidad nasa se dice que nosotros somos duales, a pesar de que soy hombre, tengo mi espíritu mujer que desde el nacimiento hasta que yo me vaya al otro espacio, me muera, seguirá acompañando todo el tiempo." 
Hasta ahora apenas contamos cuatro espacios definidos por el sexo, más el centro, el ombligo. No obstante, ahora se complican las cosas: cada persona, cada cuerpo tiene cuatro espacios -dos femeninos, dos masculinos- más el centro, el ombligo. Pero ahora ya viene la parte espiritual de lo material-físico, del cuerpo: el espíritu guardián, que es masculino para la mujer, femenino para el hombre. $\mathrm{O}$ sea, he aquí que estamos hablando de una estructura hexaléctica de la persona. Como hasta el momento nos habíamos olvidado del hecho que todo el universo nasa-andino está animado, que todo lo que exista -humanos y no-humanos (plantas, animales, piedras, minerales)- tiene su espírituguardián, su ksxa'w, que es el espíritu de noche, del Sueño, y hay que añadir que el universo, según la cosmogonía nasa, nació del Sueño-Eros-Sexo, del íntimo abrazo de los abuelos creadores Sol y Luna, Tay y Uma. Por ende, como antropólogo llego a la siguiente conclusión: cuando dos personas se unen, cuando hombre y mujer se unen, y no importa si se trata de humanos o no-humanos, tendríamos seis partes unificándose: cuatro espacios más cuatro espacios, más dos ombligos, más dos espíritusguardianes. Y si no ando equivocado, y contando bien, ya nos enfrentaríamos a doce "elementos particulares".

Ahora bien, Drexler se acuerda de sus lecturas, de sus lecciones y seminarios que dictó como Profesor de Antropología Social y Cultural a los estudiantes de las Universidades de Leipzig y Munich, sobre los temas de la "Cosmovisión Andina" y la "Introducción a la Etnografía de los Andes". Hay un pasaje de Taussig (2010), un autor que Drexler por lo menos aprecia mucho, tomado de su libro "The Devil and Commodity Fetishism in South America", donde él habla de "animated structuralism" (Taussig, 2010: 161), entendido como "this unity [...] composed of a highly differentiated system of dualities the parts of which are united through a mesh of binary oppositions."Esta es una visión del mundo andino que Drexler ya no puede compartir: No se trata de dualidades excluyentes o complementarias, ni menos de un estructuralismo que dicotomiza el universo, que piensa el mundo en oposiciones muy radicales. Pero no es así, este no es el caso para el mundo andino como Drexler lo ha aprendido a entender durante sus años de investigación de campo entre los propios indígenas. Porque fue en Colombia cuando un curandero le explicó eso de calor y frío de la manera siguiente: "Cada calor tiene algo de frío, cada frío tiene algo de calor." Eso quiere decir, que se trata de paridades, que llevan su "opuesto", su "complemento" en sí mismo ya, y por ende no es ninguna forma de estructuralismo indígena, como piensa Taussig! Mas bien, este hecho concuerda con la comprensión elemental de Descola (2012: 434 \& 439) cuando él escribe sobre el pensamiento del "analogismo" (y de éste se trata en el caso del mundo andino) que esta ontología funciona según la modalidad del "todo está en todo y recíprocamente".

En la literatura respecto a la cosmovisión andina se encuentra con frecuencia el término "dualidad complementaria" (vea Baumann, 1994; Bettin, 1994; Lozada, 2006, entre otros). Lajo (2006: 81) en su obra "Qhapaq Ñan. La Ruta Inka de Sabiduría" habla de "la primera ley del pensamiento andino", el "yanantin" que él traduce al castellano como "la dualidad complementaria". Para explicar esta ley andina, él se refiere al mito de la pareja primordial Manco Qhapaq y Mama Ocllo que salieron juntos del lago Titicaca. En un trabajo anterior, "Qhápaq kuna ... más allá de la civilización", este autor usa los términos "paridad", "dicotomía", "opuestos complementarios" como sinónimos, sin ninguna diferenciación: "En este sentido lo diferente de la cosmovisión indígena, como lo veremos después, es que de inicio se parte de conceptuar el origen del todo como una dicotomía o paridad, en donde en el principio hay dos elementos diferentes, dos esencias que entre otras características tienen la de ser complementarias y proporcionales" (Lajo, 2002: 9), de ser la "unión de los opuestos complementarios"; y Lajo (2002) menciona a la pareja "illa wi", este "ídolo" Puquina de llave (Lajo, 2002: 19), el "par-primordial [...] que representa un varón mirando al oriente y una mujer mirando al poniente, ambos envueltos de serpientes "coas" y "asirus". Al encontrar esta relación de proporcionalidad de la pareja-primordial, surge la operación geométrica de obtención de la cruz cuadrada o cruz del Tiawanacu." (Lajo, 2002: 20).

Según el punto de vista de Drexler, el mismo discurso tanto indígena como indianista está marcado por el pensamiento antropológico. Él Insiste en el hecho de que los términos "dualidad" y "paridad" son distintos. Primero antes que todo prefiere el término "paridad", o bien "pareja" ("par"), debido a que es un término más concreto, un término del "pensamiento concreto" que caracteriza al "pensamiento salvaje" de los indígenas muy en el sentido de Lévi-Strauss (1962). Segundo, como se había explicado al princípio de este ensayo, nosotros somos paridades-pareja-pares -peetam/phtam 
$w e$ 's $x$ - ya, debido a que todos tenemos estas dos energías en un solo cuerpo, y por esto ya somos complementarios, mientras que la "dualidad" sugiere que no fuera así. Hace más de un siglo los sociólogos y antropólogos hablamos de sistemas duales de clasificación, desde los tiempos de la escuela francesa de la sociología de Durkheim \& Mauss (1903). No cabe la menor duda: ¡Es obvio que este discurso sociológico muy valioso de dualidades ha encontrado su entrada al propio pensamiento de los intelectuales indígenas!

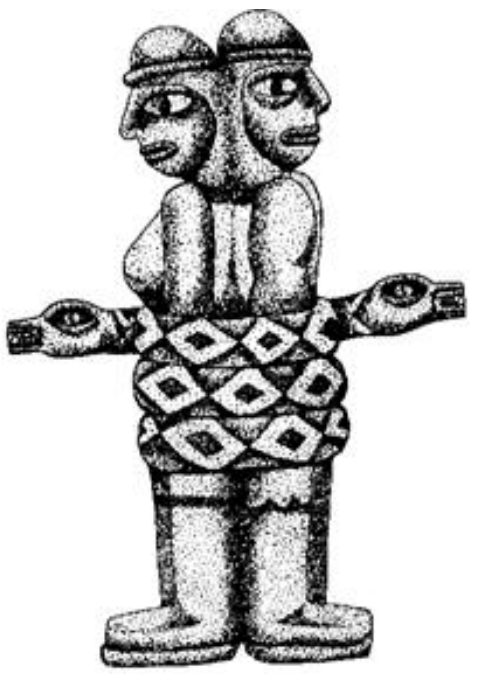

Figura 2. La pareja «illa wi» o «idiolo» Puquina de llave (Lajo, 2002: 19).

El concepto de la paridad; sin embargo, es clave para entender el mundo andino: tanto a nivel de la cosmovisión, de la cosmo-convivencia andina, como para analizar las implicaciones sociales, desde la perspectiva de la antropología social. Pues se trata de un cosmos organizado en paridades que se conectan y desconectan en el espacio-tiempo, un cosmos, donde no se trata tanto de entes, sino de relaciones, un cosmos en este sentido posestructuralista-mítico. Por ende, un rasgo común de los humanos y no-humanos es su constitución relacional; y por consiguiente, he aquí que tenemos una ontología relacional (Bird-David, 1999; Viveiros de Castro, 1998). Pero no se trata de una "telaraña cósmica" (Münzel, 1985), porque aunque la telaraña interrelaciona todo, sin embargo no tiene movimiento, le falta el dinamismo, la dimensión del tiempo. Por esta razón, se prefiero hablar del "micelio fúngico" (Ingold, 2006; que biológicamente no es ningún "rizoma", y ahí se equivocaron Deleuze \& Guattari, 2004). Siguiendo a Descola (2012) la cosmología andina representa una ontología de "analogismo" (cosmocentrismo), con diferentes relaciones "mereológicas" 5 entre partes y totalidades, entre multiplicidades y singularidades (vea Halbmayer, 2012). Como los no-humanos (fenómenos de la naturaleza, animales, plantas, piedras, espíritus) pueden ser actuantes, se puede hablar de relaciones entre colectivos humanos y no-humanos (siguiendo Latour, 1991). Aclara Descola (2012: 363): el término "colectivo" se toma aquí en el sentido en que lo ha popularizado Latour (1991), es decir, como un procedimiento de reunión, de "recolección", de humanos y nohumanos en una red de interrelaciones específicas; en esta acepción, se distingue de la noción clásica de "sociedad" en razón de que ésta no se aplica de derecho sino al conjunto de los sujetos humanos, apartados debido a ello del tejido de relaciones que mantienen con el mundo no-humano.

\footnotetext{
${ }^{4}$ Descola (2012: 301) define la ontología del analogismo, como sigue: "Entiendo por ello un modo de identificación que fracciona el conjunto de los existentes en una multiplicidad de esencias, formas y sustancias separadas por pequeñas distancias, a veces ordenadas en una escala graduada, de modo que resulta posible recomponer el sistema de contrastes iniciales en una densa red de analogías que vinculan las propiedades intrínsecas de las entidades distinguidas. Esta manera de distribuir las diferencias y correspondencias legibles sobre la faz del mundo es muy común [y para Descola la ontología del analogismo es característica para los pueblos indígenas de Mesoamérica y el mundo andino; comentario Josef Drexler]."

5 Halbmayer (2012) creó el término "mereology" que se deduce del sustantivo griego meros, "parte", para caracterizar a cosmologías que se distinguen por el rasgo de "parthood relations".
} 
Como todo el universo es vivo, animado (por eso tiene aspecto de animismo) y esos colectivos están interrelacionados (ontología relacional), se trata de relaciones sociales que están determinados por tres principios (compare Descola, 2012: 447-461): la reciprocidad simétrica (intercambio obligatorio y simétrico de bienes y servicios), la depredación (asimetría negativa), y el don (asimetría positiva; un acto voluntario, de generosidad). Aunque hay sociedades donde dependiendo del contexto socio-cósmico estos tres modelos existen simultáneamente, no obstante parece que siempre habría un modelo dominante. Para el caso de la nasa se trata del modelo de la reciprocidad simétrica. Pues cuando el sabedor espiritual Luis Yonda Copaque, interpreta la avalancha de lodo que ocurrió en el territorio de los nasa en Tierradentro el 6 de junio de 1994, él habla de "pagamento", de"sacrifício" que cobró la misma naturaleza, como "impuestos espirituales" debido a que había rupturas y desconexiones entre humanos y naturaleza. Los nasa ya no habían cumplido con las normas culturales de reciprocidad, del "Derecho Mayor" (peweçxa'), sino abusaron de la naturaleza en forma de depredación. Pero las mismas leyes de reciprocidad nasa mandan: "Yo te doy, y tú me das!" Por esto la naturaleza cobró sus impuestos espirituales en forma de sacrifícios humanos.

Aparte de la diferenciación vertical de la casa grande del cosmos en tres casas (vea arriba), los nasas diferencian el espacio de su cosmos en un lado "izquierdo" y en un lado "derecho". Mientras que el lado derecho connota las fuerzas más "positivas", masculinas, calientes, como por ejemplo con el Sol (tay), el oriente-sur, la claridad de la luz de día, y el médico tradicional bueno, se relaciona el hemisferio izquierdo con las "energías" femeninas, frías, sagradas; entre otros, con la Luna (uma), el occidente-norte, la oscuridad de la noche, con el brujo y con la "nube negra" (pta'z). Este sistema de clasificación recuerda a la teoría de "ambivalencia" y a la teoría de la "polaridad de lo Sagrado" (Caillois, 1950; Hertz, 1973), y según Bataille (1974) el hemisferio izquierdo del universo representa un "sagrado izquierdo, heterogéneo". Este concepto de un mundo "en paridades" -las paridades predominantemente femeninas a la izquierda, unas paridades más masculinas que predominan en la parte derecha del cosmos- tiene consecuencias tanto para la vida cotidiana como para las prácticas rituales; así por ejemplo tratan los chamanes por medio de sus "soplos" (mputya') de desviar la suciedad socio-cósmica ( ta $^{\prime}$ 'z) hacia la izquierda, lejos de la sociedad nasa, cuando este sucio amenaza establecerse en la parte derecha. De esta manera, ellos evitan que esta "basura" patógena les haga daño.

Pta'z es uno de los conceptos más profundos de la cultura nasa (compare Bernal Villa, 1954; Drexler 2012: Gómez Valencia, 2000). Pta'z es la "nube negra (tab kutçx) [...] y es esta nube negra que me ataca", como explica el médico tradicional Larry Jeromito (comunicación personal). Pta'z resulta de la ruptura de las relaciones socio-cósmicas, siendo "todo aquello que afecta negativamente las relaciones sociales de convivencia y con el entorno natural territorial" (Gómez Valencia, 2000: 35). Esto sucede cuando los hombres no cumplen con las reglas de reciprocidad entre ellos mismos y la naturaleza; cuando ellos no les "piden el permiso" (peweçxa') a los espíritus dueños de los recursos naturales y cuando ellos no les ofrecen la parte debida de las cosechas al duende (klxum). Así también resulta $p t a ' z$ cuando hay mucha envidia y brujería (daños) entre la gente cuando, por ejemplo, se colocan "cosas sucias" o "trapos sucios" con la sangre de la menstruación o se echa sal en los cultivos que enferma al guardián ("cuidandero") de la finca, al klxum, el cual a su vez enferma a los cultivos, a los animales y a las personas humanas. No solamente son las relaciones sociales de convivencia intraétnica que atraen al pta'z sino también las acciones de personas "de afuera", como por ejemplo de la guerrilla o del ejército. Esa "enfermedad venidera" que representa a la violencia de la guerra civil colombiana "chamusca" (quema) con el "hielo de los muertos" al territorio, a los seres humanos, a los animales y a los espíritus persona. Anualmente tratan los médicos tradicionales de desviar este "hielo" por medio del ritual de "la apagada del fogón" (ipx fxîçxhaya'): "Con el humo del fogón empujamos el hielo de los muertos, lo soplamos y lo alejamos para que no haya esta enfermedad [la violencia] en nuestro territorio." El pta'z -los nasa entienden al pta'z como "sucio", "mugre", o también como "energía mala y negativa"- es una amenaza permanente, una fuerza socio-cósmica negativa, que está relacionada con el espacio de la izquierda, con lo femenino, lo heterogéneo y lo sagrado. Esta es una lucha que los chamanes tienen continuamente para evitar el "desequilibrio" cósmico, el pta'z.

Pero ¡ojo! aunque este $p t a ' z$ constituye una amenaza permanente, una fuerza socio-cósmica negativa, que está relacionada con el espacio de la izquierda, y por ende con lo femenino (la 
menstruación puede transmitir esa energía negativa), lo heterogéneo y lo sagrado izquierdo; no obstante, no se trata de ninguna manera de ninguna concepción misógina o forma de machismo indígena. Esto aclara Luis Yonda Copaque: pues los masculinos también menstrúan cuando por ejemplo eyaculan. $\mathrm{O}$ sea, no se trata de echarles toda la culpa a las mujeres cuando ese $p t a^{\prime} z$ amenaza el equilibrio socio-cósmico. Incluso, la misma sangre de menstruación puede servirle como ofrenda, como abono, como comida enterrada a la propia madre tierra.

Como el cosmos andino es un universo organizado en pares-parejas-paridades, los humanos deben buscar el equilibrio, la armonía del socio-cosmos. A este ideal cultural se refieren las siguientes frases del Nasa Yuwe: "wêt wêt fxizenxi", o bien "eçx eçx fxizenxi". wêt quiere decir "lo sabroso", "vivir sabroso, feliz"; eçx, se refiere a la alegría, a la parte lúdica, como el movimiento también genera mucha alegría y tranquilidad; eçx eçx, por consiguiente, tiene el significado de "contento contento". Otros términos que los nasas emplean en este contexto, son kwe'sx kiwe fxizenxi, que significa "nuestro territorio fresco", o "nuestro territorio feliz", y wêt wêt ûs kiwe nxi'. wêt wêt se refiere a los estados emocionales de "estar feliz", de "felicidad" y de "salud". Mientras que $\hat{s}$ es "lo que permanece o lo que ha sido", se entiende bajo el sufijo nxi' la vida que uno lleva de acuerdo a esta forma ética, el resultado de esta forma de vida. Con la palabra kiwese representa el "territorio de los nasa" (nasakiwe), y por extensión el cosmos en general. wêt wêt ûs kiwe nxi' se refiere por consiguiente a la salud y al bienestar emocional de los seres humanos, de los animales, de las personas espíritu y del territorio, cultura entendida como el resultado de una vida en armonía con el territorio. Esto quiere decir que estas nociones constituyen tanto el ideal cultural como el resultado de las relaciones "frescas" de la solidaridad, del compañerismo, de la reciprocidad de su cosmos social. Este "equilibrio" nasa; sin embargo, no es ningún equilibrio "horizontal", comparable a una "libra", sino un equilibrio "vertical": así por ejemplo el resultado de un ritual de limpieza y armonización debe ser "jeb puuk", "lo izquierdo abajo", o bien "la enfermedad abajo".

Tanto las nasas como los kichwa comparten la concepción y cosmo-convivencia de un mundo organizado en paridades. Como mostraron Earls \& Silverblatt (1976), refiriéndose a la descripción de Santa Cruz Pachakuti Yamqui (1613) del cosmograma de Coricancha, del templo incáico del Sol en Cuzco, estos modelos cosmológicos son una representación de los principios de interacción de ayni (reciprocidad socio-cósmica; en Nasa Yuwe puukx jáda), tinku (el encuentro, el choque de contrastes que puede causar un pachakuti, la inversión del tiempo-espacio) y amaru (el izquierdo femenino, factor de inestabilidad y desequilibrio, algo como un motor de la dialéctica negativa; en Nasa Yuwe pta'z). Mientras que el modelo cosmológico del imperio incáico estableció un sistema de dominación teocrática justificando el modo de producción tributario (compare Earls-Silverblatt, 1976; Godelier, 1989: 189,ss) -el Inka como hijo del Inti-Sol ejercía el "doble monopolio" sobre los medios "imaginarios" y reales de la producción económica y de la reproducción de la vida (objetos sagrados, fórmulas rituales, el control sobre la tierra, el trabajo y sus productos; vea Godelier, 1998: 271)-, después de la conquista española y el cobarde asesinato del Inka en las sociedades andinas de lo Contemporáneo siguen vigentes estos tres principios socio-cósmicos.

Por medio del concepto de paridades socio-cósmicas se establece el principio de reciprocidad (ayni): en el modelo incásico, que era una sociedad de clases, esta reciprocidad (entre las dos mitades de paridades cósmicas) incluye la redistribución de los bienes (servicios, prestaciones) desde abajo hacia arriba - de la gente común hacia los dioses, especialmente el Sol y su hijo en la tierra, el InkaRey); es un modo de producción tributario que está legitimado por la cosmología religiosa (Wolf, 1999); se trata pues del intercambio de una garantía de la estabilidad del cosmos otorgada por el inca contra la prestación de trabajos serviles y el pago de tributos en su beneficio, como el Inca - el hijo de Inti-Sol - era la fuente de la fuerza vital, de la fuerza cósmica. Muy por lo contrario, en el caso de los nasa, que es una sociedad profundamente igualitaria, esta redistribución se practica hacia los "dueños" espirituales del cosmos, en forma de ritos y de ofrendas es la "cuarta obligación del don" en el sentido de Mauss (1925), que se refiere a los dones de los hombres a los dioses como dueños verdaderos de las cosas, de los recursos naturales, etc. (vea Godelier, 1998: 49ss.). Tanto la sociedad incaica como la sociedad nasa eleva la "reciprocidad" -el compañerismo, el compartir, las ofrendas- aun nivel religioso-cosmológico. Falta resaltar que los indianistas de hoy ponen hincapié a los aspectos bondadosos del imperio incásico: Según el mapuche Pineda (2005) "la economía fue puesta por los incas al servicio de la sociedad", y por ende el Tawantinsuyu incásico representa el modelo de un 
socialismo comunitario. No por último, por consecuencia de esa visión del mundo dividido en columnas de contrarios, en dos mitades de paridades que componen el cosmos, surge otro tema casi obsesivo del mundo andino, de la runasofía que es la "filosofía dinámica del equilibrio" (ReichelDolmatoff, 1986: 81).

Por el contrario, amaru y $p t a^{\prime} z$ significan la inestabilidad permanente: Las tradiciones kichwa modernas relacionan $k^{\prime} o a$ con un monstruo felide, que vive arriba en los puquios de las montañas. Desde arriba se puede elevar en forma de una nube al cielo y lanzar granizo para "robar las cosechas". Por esto, en la región de Cuzco se practica el ritual de apaciguar a koa-amaru por medio de ofrendas. Total que "amaru" simboliza la acción de las fuerzas que se hallan en un estado de desequilibrio y afuera del control humano (Earls \& Silverblatt, 1976: 314). No obstante, cuando los humanos observan el código socio-cósmico moral (la reciprocidad, la generosidad del don y del compartir), este amarú-pta'z no se manifiestan. Por otra parte, este amaru/pta'z representa en mi interpretación (compare Drexler, 2007 \& 2012) -siguiendo a la escuela izquierda de la sociología de la religión francesa de Durkheim \& Mauss (1903)- un principio revolucionario, dinámico, izquierdofemenino que hace posible el pachakuti, la inversión o bien subversión del espacio/tiempo como se puede observar en los movimientos revolucionarios de Tupak Amaru (Katari), o bien en el hecho que los nasa durante las recuperaciones de tierras les colocan sustancias sagradas de pta'z a las fincas de los terratenientes (las que van a ocupar), y tapan los caminos que conducen a su territorio con esas sustancias poderosas. Pensándolo de esta manera, el pta'z/amaru es un medio/ motor en la lucha de clases.

Cada sociedad se basa en una serie de sistemas de oposición (Foucault 1967). Se basa en una serie de sistemas de oposición para establecer un código moral para que pueda funcionar la sociedad en cuestión: en nuestro caso del mundo andino se establecen e hipostasian los principios de la reciprocidad, del equilibrio (fxizenxi, en Nasa Yuwe), y del desequilibrio (amaru-pta'z-pachakuti) en un nivel religioso.

"Sistemas de oposición": Para el mundo andino, nosotros no hablamos ni de "dicotomías", ni de "dualidades". Somos paridades, nosotros los humanos y los no-humanos, los masculinos y las mujeres, y los masculinos cargamos el peso del pta'z adentro, no solamente cuando eyaculamos, sino pensemos en nuestro Alter Ego, nuestro Otro Yo, que es nuestro espíritu-guardián femenino. El mensaje andino sería pues que lo absolutamente bueno, y lo absolutamente malo no existen, esto sería una visión muy radical, una visión del Maniqueísmo. Un solo cuerpo: dos energías, cinco espacios, un Otro Yo (Alter Ego) espiritual-pareja. Nosotros somos seres pareja, llevamos los complementos en nosotros ya.

\section{PARIDAD, RELACIÓN Y FUERZA (YANANTIN / CHIMAPURANAKUY / SINCHINAKUY)}

El Dr. Rosendo Rojas de la Universidad de Cuenca, junto con Polibio Chalán, Yachak ("Conocedor conocido") kichwa del pueblo Saraguro, proponen dentro de la cosmovisión andina a la paridad y su relación con el movimiento y fuerza. Para ellos en el mundo kichwa, la entidad básica (tantanakuychani) es la conexión colectiva/comunitaria (puranakuy). Un ser o realidad totalmente separado y aislado es inimaginable; sería el máximo grado de la abstracción; es decir, un no ente. La entidad básica -(tantanakuychani) como lógica-, integra elementos y experiencias: afectivos, ecológicos, éticos, estéticos, productivos, de poder e interacción. La relacionalidad deriva y se concreta en una convivencia en el cosmos. La desconexión absoluta -rakinakuy-no es posible, es una separación, una pérdida de la conexión, incapacidad o imposibilidad de conectarse con los otros.

Cada acontecimiento -imatukuy- es un estado de conciencia, emoción -llaki/kushikuy-, afecto o sentimiento -yarina-, hecho, posibilidad; se halla inmerso en múltiples relaciones con otros entes, sucesos inesperados, estados de conciencia, sentimientos, hechos, posibilidades. La realidad es una red cambiante de relaciones, de conexiones parciales. La realidad -shutipacha- es subjetiva yaypacha- y objetiva -rikuypacha-, cognoscente y conocida, es trans-conceptual y conceptual: es una 
realidad posibilística y cuántica, es onda y partícula. La realidad no soporta el ejercicio dicotomizante, polarizado.

Yanantin (paridad) exige la convicción de ser parte de algo que es contradictorio, la oposición hace viable la vida; lo contradictorio es la razón de ser y estar de los otros diferentes como elementos de la propia existencia; lo contradictorio es una condición de la posibilidad de estar en el mundo; influye en el hacer y se materializa en el ser. Runana (acción, hacer) kana, (ser/estar). Yanantin es dos cosas hermanadas; es igual que la vista que coordina a los dos ojos, siendo diferentes ven una misma imagen.

Los distintos elementos, regiones o experiencias -kaushashkapacha- de pacha (tiempo/suelo, lugar) en tanto mundo real presente; también pares por necesidad, se corresponden de una manera armoniosa; es una múltiple direccionalidad compartida. Los correlatos (chimpapuray) de la paridad son simbólicos (rikchaylla), comprensiones diversas del hacer, de los ritos (challay), de los mitos (ñawparimay), es una escena orquestada de la realidad, a su vez temporal y difusa.

Es una experiencia performativa en donde el hacer se confunde con el decir; al decir se hace; mundos simbólicos, virtuales, mágicos y reales se funden en una oleada que impregna a los implicados en una o más conexiones parciales. Hay que hacer para poder decir; acción idea son un mismo momento/espacio; es en los haceres que se concretan los símbolos y los comportamientos. El símbolo es parte, está conectado, concretado, se corresponde con aquello simbolizado.

Yachararay es estar aprendiendo algo de manera constante y permanente en todas las circunstancias de la vida.

Los individuos de la paridad son pares de antemano; nadie es uno solo ni tiene una sola dirección y un solo futuro. Son múltiples mundos posibles que se concretan en pares conectados. En inclusión y la exclusión (paktachina/chikanyachina) está la potencia (sinchi) de la paridad. Los par/pares se conectan/desconectan (tandanakuy/rakinakuy) en una interface energética inestable. La paridad/disparidad (chulla chulla) se da en el eterno movimiento (pachakutik), un espiral inestable. Es posible y necesario estar dentro y fuera (uku/kancha); arriba y abajo (hanan/urin), a la izquierda o la derecha (lluki/allawka), masculino y femenino (kari/warmi) a la vez.

$\checkmark$ La paridad es vibración (chukchuy), caos, determinación y libertad (kishpipacha). La paridad es vida (kawsay) y naturaleza. La desconexión cambia al conjunto de pares, así como la conexión, el convivir/estar pareado fortalece a la comunidad y permite que el don fluya.

$\checkmark$ La paridad es diálogo -rimanakuy-, oposición y silencio -chunlla- a la vez y de manera distinta cada vez.

$\checkmark$ La paridad encuentra el sentido cuando el movimiento permite saltos en calidad, la paridad no es anodina, simplista o intrascendente.

$\checkmark$ La paridad es equilibrio (nankay) en movimiento (kuyuri) están fundidas en ella la identidad y la diferencia (chikanyay) en medio de la variación y la diversidad (tawka).

$\checkmark$ Las ondas (kinku) dependen de una materialidad-imakay-corpuscular que su vez no tiene sentido sin el aporte de la onda/conciencia elemental.

$\checkmark$ El hacer desconectado, autónomo, solitario, disparejo, es un ente incompleto (manapakta) no concebible e irreal (illak), incapaz de ser virtual o imaginado (yuyaypilla).

La dinámica de la paridad es su fuerza, potencia, concreción de mundos posibles. Los elementos pares/pareados exigen una tercera potencia que les conforme y libere. Es la mirada (rikuna) del otro la que conforma al ser. Se habla con el lenguaje de los otros; se vive colectivamente en sincronías/diacronías. Los otros están dentro de un par, en movimiento permanente, en búsqueda de nuevas conexiones parciales. Nadie es igual a sí mismo en el segundo siguiente. Un horizonte de múltiples sentidos rodea al par; comparte calores y colores (kunuriltullpuy); no existen la indiferencia ni el calor ni el frío extremos, la armonía (allikay) depende de quiénes y de qué manera la perciban.

Coros de voces, disonancias, múltiples melodías colectivamente atadas a experiencias concretas. La contradicción es una realidad; una fuerza motriz, es la necesidad de los consensos (kamachinakuy) nunca alcanzados pero siempre añorados. 


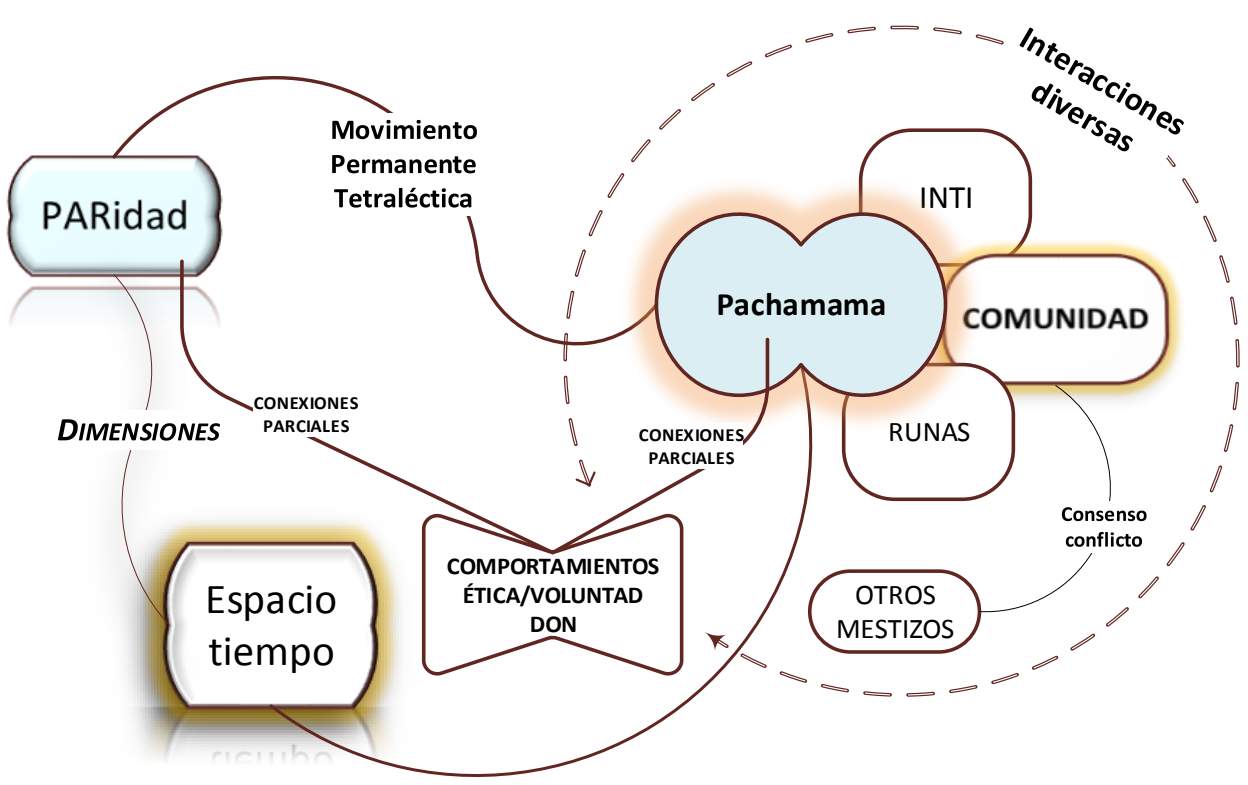

Figura 3. Paridad-relación fuerza (Elaboración: Rosendo Rojas).

La fuerza motriz de la paridad cataliza la realidad pareada con múltiples mensajeros.

$\checkmark$ La paridad es el lugar, nicho del estar, del ser. Es la posibilidad de existencia de lo sumak -bello-, de lo armónico, de la comunidad (ayllu).

$\checkmark$ La paridad exige la conexión como estado, como aspiración de la sanación (hampipacha); la paridad es la medida del grado o las vías de la desconexión y de las posibilidades del retorno.

$\checkmark$ Paridad y vida son dos experiencias inseparables (tinkipacha). La paridad es la base del (sumakawsay). La paridad es también pasaje, vacío, abismo, oscuridad que espera la luz (tutapacha/achikpacha).

$\checkmark$ Paridad es convivencia armónica (chikanpuraallikawsay), es la posibilidad del placer y del agrado (sumakyarina) así como de la desconexión como protección de la comunidad en peligro. La paridad es el lugar de la amistad-mashi- y del amor-kuyay-; del desamor y el desencanto.

$\checkmark$ La paridad está en la belleza del monte sagrado -ushnuurku-, en las aguas plácidas y en las correntadas; en las piedras -rumi- y en el cielo -hawapacha, en el arco iris -kuychi, en la lluvia -tamya- y la tormenta -illapa-; en el fuego -nina- y el viento -wayra-.

$\checkmark$ La paridad junta lo grande -hatun-cosmos -pamaway-como lo pequeño-uchilla-, territorio -llaktariallpa-. Es tiempo y espacio.

$\checkmark$ La paridad es asimetría, competencia, conflicto, paz-makanakuy/kasillakuy-. Pasado y futuro -ñaupa/shamuk pacha-, aura y cuerpo -rity/ukku-.

\section{EL PRINCIPIO DEL YIN-YANG《 BAP阳》}

La teoría del Yin-Yang a pesar de la distancia coincide con la visión andina de paridad en varios aspectos, como cálido-fresco, kari-warmi, en el mismo sentido de un nivel de energía que se expresa como opuestos. Este principio de la filosofía tradicional china y andina permite clasificar, ordenar, observar y analizar los fenómenos y sus relaciones, es así que en el estudio de las plantas medicinales pueden haber plantas cálidas y frescas, y warmi o kari; y es más, una misma planta puede tener una parte kari y una parte warmi, lo que coincide además con el sentido filosófico de lejano oriente de comprender a los objetos en movimiento, en una interrelación dinámica. En la filosofía china la paridad alcanza su mayor expresión con la teoría o principio del Yin-Yang que considera que todo el 
mundo puede entenderse comprendiendo estos dos aspectos o fuerzas; en concordancia con el principio universal de relación entre los objetos, todo puede clasificarse y todo contiene Yin-Yang.

El Profesor Zhou Xue-sheng (2007) de la Universidad de Medicina China de Nanjing (nanjingzhongyiyaodaxue) 《南京中医药大学》 considera que el Yin-Yang es un principio filosófico chino para comprender los fenómenos de la naturaleza y explicar sus cambios. El Libro de las Mutaciones (yijing)《易经》 escrito aproximadamente en el año 1.200 antes de nuestra Era, recoge valiosa información sobre algunos principios filosóficos, especialmente sobre las teorías del YinYang como opuestos; desde su denominación explicita la importancia del cambio para la comprensión del Universo (cosmos) y la naturaleza, y la paridad que puede apreciarse desde su nombre. El carácter “yi"《易》, está formado por el radical Sol "ri" 《日》, en la parte superior y por el radical "yue" o Luna 《月》, en la parte inferior; el Sol representa al Yang, lo masculino; y la Luna a lo Yin, lo femenino.

En libro de Pensamientos Sencillos (yizhuan) 《易传》escrito en el Período de los Reinos Combatientes (475-221 a. C) que contiene comentarios de filosofía y ética menciona que "Yin-Yang hacen el camino" (dao) 《道》, recordemos que dao es un término clave en la filosofía china que es traducido como camino, senda o sentido y es el núcleo básico del taoísmo; a su vez se puede afirmar que el dao es la fuerza superior que contiene al Yin-Yang (Zhou, 2007). Un común aforismo antiguo ratifica esta concepción (yiyinyiyangzheweidao) 《一阴一阳之谓道》que quiere decir: "un aspecto yin, un aspecto yang, esto es el dao".

En el Canon de la Medicina Interna del Emperador Amarillo (huangdineijing)《皇帝内经》en su II tomo llamado Eje Espiritual” (suwen)《素可》menciona el Yin-yang y la correspondencia con los objetos y fenómenos de la naturaleza, ratifica la visión de camino, no como vía de comunicación física, sino energética: Yin-yang es el camino, el cielo y la tierra, la guía de los principios de las cosas, el origen del cambio, la raíz de la vida y la muerte, y la residencia de la brillantez del espíritu".

Como puede observarse la teoría del Yin-yang es una idea fundamental para explicar la interacción entre los aspectos opuestos de cosas o fenómenos del Universo. El sentido original proviene de una analogía: el sol ilumina una montaña, con partes expuestas al sol y partes en sombra, el lado expuesto al sol es de naturaleza Yang, el lado oscuro es Yin; la idea de montaña tiene el sentido de unidad. Así, aunque representan dos fuerzas aparentemente opuestas, forman parte de una única naturaleza. Esta definición no sólo refleja la polaridad básica del Yin-Yang, sino que además indica su capacidad para transmutarse el uno en el otro, porque así como a medida que el Sol se desplaza por el Cielo, el lado de sombra de la montaña se va llenando de Sol y el lado que inicialmente tenía Sol va quedando en la sombra.

El Clásico de la poesía o Libro de los Cantares (shijing)《诗经》escrito cerca del año 305 en el mismo Período de los Reinos Combatientes, ratifica esta analogía: “... mira la cima de la montaña, observa su Yin y su Yang y mira el florecimiento de la primavera". El libro de Explicación de los caracteres (shuowen) 《说文》 aparecido en el año 121 de nuestra era durante la Dinastía Han explica el significado de Yin-yang, Yin significa obscuridad, las playas de arena del sur del río, mientras que la vertiente norte de la montaña, la parte alta y brillante son Yang hay que recordar a China como una nación que está en el hemisferio norte, y las alineaciones, referencias geográficas vienen en este sentido. En relación a lo externo e interno, el filósofo Laozi《 $t$ t子》 propone que todas las cosas por dentro llevan el Yin y son abrazadas externamente por el Yang (Laozi, 604 a. C).

\subsection{Categorización fenomenológica del Yin-Yang}

Todos los seres, objetos, fenómenos y cosas del Universo o cosmos tiene dos aspectos o fuerzas opuestas y correspondientes de una misma energía simbolizadas por el Yin y el Yang; que en el Libro de las Mutaciones es "energía creadora" y proviene del Cielo, en tanto la Tierra es la receptora y fecundadora de esa energía primaria o esencial.

Para el libro de las mutaciones toda creación y todo cambio responden a la polaridad dinámica del Yin y el Yang, que son propiedades de la energía activa, no de la materia estática. Su primera representación es como trazos continuos o cortados como se observa en la Tabla 1. 
Tabla 1. El Yin y Yang en el Libro de las Mutaciones (Elaborado por David Achig).

\begin{tabular}{cc}
\hline Elemento & Representación \\
\hline Yang & \\
Yin & \\
\hline
\end{tabular}

Pronto surgió la necesidad de profundizar más en las respuestas a las interrogantes de la vida, la salud y más, por lo que aparecieron combinaciones de estos dos trazos simples, surgiendo las cuatro combinaciones posibles interpretadas como un carácter Yin o Yang predominante; a estas cuatro fases se le puede añadir una quinta fase o neutra que se representa con un círculo "O"; es una fase para recibir y armonizar las otras cuatro (Tabla 2).

Tabla 2. Los cuatro bigramas (Elaborado por David Achig).

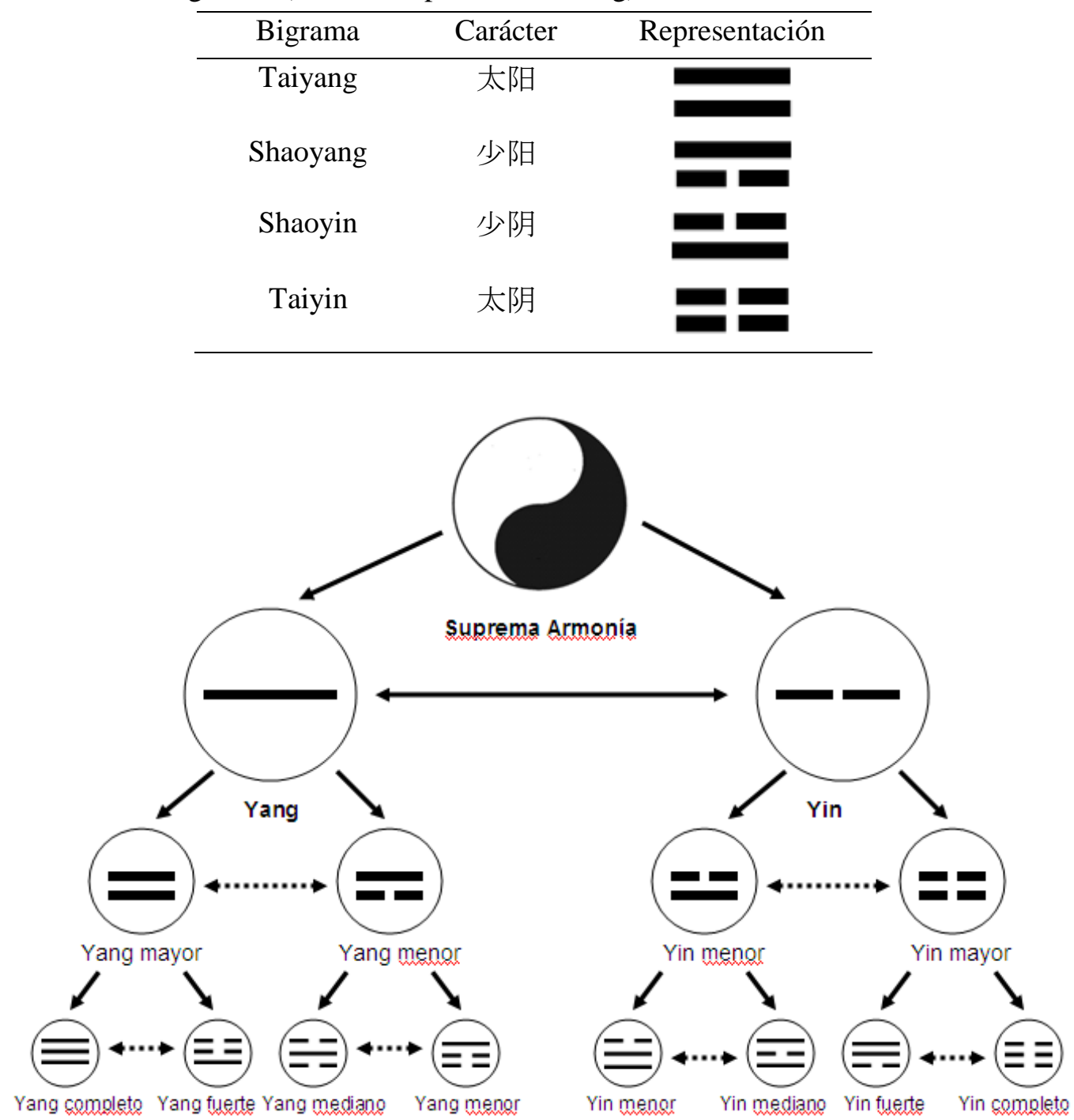

Figura 4. La suprema armonía, bigramas y trigramas (Elaborado por David Achig).

Los bigramas no fueron suficientes para dar respuestas a los cuestionamientos sobre el Universo y la naturaleza; es así como se añade un tercer elemento, que no solamente es lineal, sino filosófico. Aparece el primer trigrama como la unión entre el Cielo y la Tierra, gracias al hombre; "entre el Cielo y la Tierra está el Hombre"; además se trata de una referencia matemática manifiesta por el número 3, resultante de la suma aritmética del Cielo, representado por el número 1 y la Tierra, representada por 
el número 2. Luego los trigramas se fueron juntando en parejas, como efecto clasificador del YinYang, dando como resultado los hexagramas, ocho en total, los llamados "Ocho signos principales", “Ocho Trigramas" o “Bagua" 《八卦》 ${ }^{6}$; los hexagramas se constituyen así en la imagen de lo que ocurre en el Cielo y la Tierra.

Dentro de la consideración dialéctica para graficar los trigramas y hexagramas; la línea seguida es Yang y la línea entrecortada es Yin; la combinación de Yin y Yang crea las formas de energía y la interacción de las formas de energía crean el Universo: una energía en interacción con el Universo y la naturaleza.

Tabla 3. Relación entre los 8 Trigramas o bagua《八卦》, con la naturaleza y su cualidad (Elaborado por David Achig).

\begin{tabular}{|c|c|c|c|c|c|}
\hline Trigrama & Nombre & Pinyin & Energía & Naturaleza & Cualidad \\
\hline & 乾 & qian & $\begin{array}{c}\text { Yang } \\
\text { completo }\end{array}$ & cielo & fuerza \\
\hline & 坤 & kun & Yin completo & tierra & abnegación \\
\hline & 震 & zhen & Yang fuerte & trueno & movimiento \\
\hline & 坎 & kan & Yang mediano & agua & peligro \\
\hline & 艮 & gen & Yang menor & montaña & quietud \\
\hline & 巽 & xun & Yin fuerte & $\begin{array}{l}\text { viento, } \\
\text { madera }\end{array}$ & penetrar \\
\hline$=$ & 离 & li & Yin mediano & fuego & luminosidad \\
\hline - - & 兑 & dui & Yin menor & $\begin{array}{l}\text { lago, lluvia, } \\
\text { metal }\end{array}$ & regocijo \\
\hline
\end{tabular}

Dos son los principios elementales de la teoría del Yin-Yang:

a) Omnipresencia de la dualidad: todos los fenómenos tienen dos aspectos: Yin y Yang, dos opuestos y complementarios en busca de la suprema armonía; una muestra de la polaridad como reconocimiento indispensable de la unidad, el todo que reúne a los contrarios: "la claridad del sol" o Yang y la "ausencia de claridad", sombra u oscuridad o Yin; la oposición entre el día y la noche, la alternancia de luz y oscuridad, el movimiento que sólo es perceptible en referencia a la inmovilidad, el frío y el calor, la sequedad y la humedad, la vida y la muerte.

b) Divisibilidad infinita: todos los fenómenos pueden dividirse en Yin y Yang, además cada categoría puede volver a dividirse, por ejemplo, el invierno es Yin y el verano es Yang, pero el día en invierno es Yang en Yin, la noche en invierno: Yin en Yin; el día en verano es Yang en Yang, la noche en verano es Yin en Yang. En cuanto a órganos y vísceras:

\footnotetext{
${ }^{6}$ Los Trigramas son elementos importantes en el pensamiento filosófico de Extremo Oriente y sus manifestaciones son múltiples y populares; un ejemplo lo constituye la bandera de la República de Corea, en cuyo fondo blanco se destaca en el centro una representación de la Suprema Armonía (Yin-yang) en azul, flanqueada a sus 4 costados por los trigramas: qian «乾》, Yang completo; kan «坎》, Yang mediano; kun «坤》 Yin completo; li «离》Yin mediano.
} 
Son Yang las seis vísceras: vesícula biliar, estómago, intestino delgado, intestino grueso, vejiga y sanjiao; son Yin los cinco órganos macizos: hígado, corazón, bazo, pulmón y riñón.

$\checkmark$ Entre los órganos, son Yang: corazón y pulmón; son Yin: hígado, bazo y riñón.

$\checkmark$ Entre los órganos Yang, es Yang el corazón y el pulmón es Yin; entre los órganos Yin, el hígado es Yang, mientras que el bazo y riñón son Yin.

$\checkmark$ Además cada órgano tiene su aspecto Yin y Yang, el exterior del corazón será Yang, el interior Yin; y según su función, habrá manifestaciones Yang como taquicardia y signos Yin como bradicardia.

Tabla 4. Clasificación de los fenómenos y atributos según sus características Yin-Yang (Elaborado por David Achig).

\begin{tabular}{|c|c|c|}
\hline Atributos & Yang & Yin \\
\hline \multirow[t]{5}{*}{ De lugar } & Arriba & Abajo \\
\hline & Fuera & Dentro \\
\hline & Izquierda & Derecha \\
\hline & Sur & Norte \\
\hline & Cielo & Tierra \\
\hline De tiempo & Día & Noche \\
\hline \multirow[t]{2}{*}{ Estaciones } & Primavera & Otoño \\
\hline & Verano & Invierno \\
\hline Temperatura & Calor & Frío \\
\hline Humedad & Seco & Húmedo \\
\hline \multirow{2}{*}{$\begin{array}{l}\text { Brillo y } \\
\text { oscuridad }\end{array}$} & Brillo & Oscuridad \\
\hline & Función & Sustancia \\
\hline $\begin{array}{l}\mathrm{De} \\
\text { movimiento }\end{array}$ & Ascenso & Descenso \\
\hline \multirow{3}{*}{$\begin{array}{l}\text { Sustancia y } \\
\text { función }\end{array}$} & Función & Sustancia \\
\hline & Movimiento & Quietud \\
\hline & Rápido & Lento \\
\hline \multirow[t]{3}{*}{ De actividad } & Excitación & Inhibición \\
\hline & Hiperactividad & Hipoactividad \\
\hline & Transformación & Formación \\
\hline
\end{tabular}

\begin{tabular}{|c|c|c|}
\hline Atributos & Yang & Yin \\
\hline \multirow{14}{*}{$\begin{array}{l}\text { En el cuerpo } \\
\text { humano }\end{array}$} & Parte exterior & Parte interior \\
\hline & Parte superior & Parte inferior \\
\hline & Zona dorsal & Zona ventral \\
\hline & Vísceras & Organos \\
\hline & $\begin{array}{l}\text { Organos } \\
\text { externos }\end{array}$ & $\begin{array}{l}\text { Órganos } \\
\text { internos }\end{array}$ \\
\hline & Piel y pelos & $\begin{array}{l}\text { Tendones y } \\
\text { huesos }\end{array}$ \\
\hline & Cabeza & Pecho \\
\hline & Qi & Sangre \\
\hline & $\begin{array}{l}\text { Energía } \\
\text { defensiva } \\
\text { (weiqi) }\end{array}$ & $\begin{array}{l}\text { Energía } \\
\text { nutricia } \\
\text { (yingqi) }\end{array}$ \\
\hline & Nacimiento & Crecimiento \\
\hline & $\begin{array}{l}\text { Enfermedades } \\
\text { agudas }\end{array}$ & $\begin{array}{l}\text { Enfermedades } \\
\text { crónicas }\end{array}$ \\
\hline & Dolor & Hinchazón \\
\hline & Inflamación & Tumor \\
\hline & Catabolismo & Anabolismo \\
\hline \multirow{3}{*}{$\begin{array}{l}\text { En el } \\
\text { comportamiento }\end{array}$} & Extrovertido & Introvertido \\
\hline & Acelerado & $\begin{array}{l}\text { Lento y } \\
\text { pausado }\end{array}$ \\
\hline & Activo & $\begin{array}{l}\text { Receptivo y } \\
\text { pasivo }\end{array}$ \\
\hline
\end{tabular}

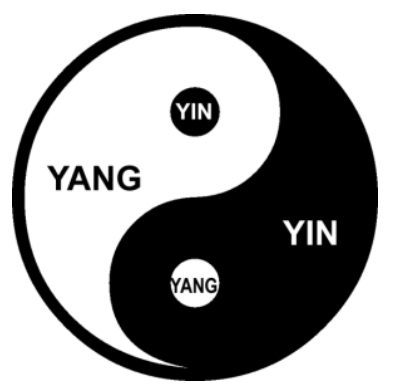

Figura 5. Representación de la Suprema Armonía o Taijitu 《太极图》(Elaborado por David Achig). 


\subsection{Representación gráfica de la Suprema Armonía}

La Figura 5 muestra la conocida representación gráfica de la Suprema Armonía o "taijitu"《太极冬》: el círculo mayor representa el espacio en donde se mueve el Qi $\$ 气》; las dos figuras internas: blanca y negra muestran el Qi en una constante generación de aumento y disminución. El color blanco representa la energía Yang mientras que el negro la energía Yin, cada fase crece hasta un punto en que inevitablemente se transforma en su opuesto; los pequeños círculos se insertan en su opuesto para completar la armonía como dicen los textos antiguos: "en todo Yang hay Yin y viceversa". La simetría en la gráfica, refleja el equilibrio entre la fuerza; el "taijitu" encierra un profundo misterio y verdad: "todo elemento contiene a su opuesto en equilibrio y armonía".

La Suprema armonía se inicia en un punto, el mismo que se extiende y forma una línea; o tal vez la línea se forma por dos puntos que se comunican entre sí.

La energía para crecer y multiplicarse y continúa en movimiento de manera constante y ordenada; es así como se van sucediendo fases de contracción y plegamiento, que generan los opuestos; y luego marcan el comienzo de una nueva fase.

\section{Los 4 principios de interrelación Yin-Yang}

a) Principio de oposición (yinyangduili) 《阴阳对立》: el Yin y el Yang son dos aspectos opuestos y antagónicos; su enfrentamiento produce un fenómeno de limitación mutua, la presencia de Yin se opone a un desarrollo excesivo de Yang y viceversa.

b) Principio de interdependencia (yinyanghugen) 《阴阳互根》: la condición previa para la existencia del uno, es la existencia del otro; son recíprocamente necesarios; no puede entenderse la existencia del día, sin la noche; de la luz, sin la oscuridad.

c) Principio de reducción y crecimiento (yinyangxiaozhang) 《阴阳消长》: el equilibrio dinámico del Yin-Yang depende de las fases alternas de crecimiento y disminución, considerando que el crecimiento del uno, reduce al otro; este mecanismo se observa en la sucesión del día y la noche, de las estaciones.

d) Principio de transformación (yinyangzhuanhua) 《阴阳转化》: en ciertas condiciones extremas, los opuestos pasan de un estado de compensación a uno de transformación; el Yin excesivo se transforma en Yang, el Yang excesivo se transforma en Yin; el frío en extremo produce calor y quema; el calor en extremo provoca frío. La reducción y crecimiento tiene que ver con un aspecto cuantitativo del proceso, la transformación es esencialmente cualitativa.

\section{DISCUSIÓN Y CONCLUSIÓN}

El objetivo del presente artículo era una crítica de los paradigmas de la dualidad y de la complementariedad: Según la "Runasofía" y la filosofía nasa, nosotros somos "completos", no necesitamos "complemento": Cada ser vivo dispone de cuatro espacios - dos masculinos, dos femeninos, más del espíritu guardián del género opuesto -, y es el ombligo - el centro - que lo conecta con los diversos espacios del cosmos. Aunque en esta perspectiva somos entes "completos", no obstante necesitamos "compañías" múltiples. Por ende, el cosmos andino es un cosmos organizado en paridades que se conectan y desconectan, y que se basa en los principios socio-cosmológicos de reciprocidad, del equilibrio y del flujo de fuerza vital cósmica en movimiento. Fundamental en el mundo andino, es la idea de una conexión colectiva-comunitaria, como siempre se trata de "dividuos" en conexiones múltiples tanto reales como posibles - un "individuo" aislado no puede existir en el pensamiento amerindio. Por ende, preferimos hablar de "pares"-"paridades", y no de "dualidad", como se trata de relaciones parciales entre distintas múltiples paridades conectándose y desconectándose, en un cosmos que se distingue por relaciones parciales, un rasgo común y característico de las ontologías del "analogismo". Mientras que la "dualidad" es el modelo "individualista" que proviene de la concepción y de la realidad euroamericana del "individuo", la "paridad" nace de una vida comunitaria 
del "dividuo" en múltiples conexiones tanto reales como posibles.

El aporte de Rosendo Rojas y Polibio Chalán subraya factores como la vida comunitaria y un mundo en conexión socio-cósmica, una vida armoniosa entre comunidad y cosmos, procurando un modelo normativo de la paridad-sociedad-cosmos. No obstante, esta "armonía socio-cósmica", está amenazada por el factor del amaru, en la versión nasa el $p t a^{\prime} z$, como el equilibrio es delicado, frágil y pasajero, y por ende requiere de la ritualidad permanente para fines de limpiar el sucio, equilibrar y armonizar el Socio-Cosmos. Especialmente cuanto más se requiere de rituales de limpieza y de armonización, cuando pensamos en los efectos a menudo y al parecer cada vez más devastadores del sistema mundo moderno como lo demostraron los análisis de Wolf (2001) quien habla de "poder estructural", o de Farmer (2004) con su concepción teórica de la "violencia estructural" de la economía política del capitalismo global. Aunque la "clasificación matemática" de la paridad tiene aspecto de una "lógica tetraléctica" - los cuatro espacios, las cuatro direcciones del cosmos, así como las cuatro partes del cuerpo humano, la misma cruz andina (chakana) -, hay que evitar cierto formalismo, como demuestra la experiencia Drexler's del marzo pasado, cuando el sabedor espiritual Luis Aureliano Yonda Copaque le realizó un ritual de limpieza en Popayán. Mientras que ambos estaban "mambeando" hojas de coca y otras sustancias sagradas, soplando, sacando y escupiendo este sucio, la enfermedad Drexler's - según el diagnóstico por medio de sus diálogos con los abuelos, los mayores del espacio, él sufría del "arco rojo" -, Luis le explicó cada fase del ritual explicando la matemática nasa:

"En inicio de la sesión de la limpieza siempre se empieza en hacer la consulta espiritual para coger la energía de la persona quien consulta, seguidamente se limpia los cuatro espacios del territorio conceptualmente en el espacio espiritual de los nasnasa es lo infinito, o más bien el universo, y la quinta mambeada [masticar hojas de coca con cal, Drexler] se hace el volteo de la jigra limpiando el universo de las enfermedades que manifiestan a través de la lectura de la naturaleza y el cosmos; seguidamente se armoniza con plantas frescas, después de haber hecho la limpia del universo, se procede a limpiar el cuerpo de la persona, también cuatro mambeadas y la quinta para limpiar mediante el volteo de la jigra, relativamente la quinta no es la única puede ser mas de acuerdo a las señales del cuerpo. Lo del tabaco es una planta muy fuerte para limpiar ya que se complementa con el abuelo fuego, tabaco y fuego sacan las malas energías que se impregnan en el cuerpo físico material y espiritual, por ello la importancia de esta abuela tabaco sagrado, y el fuego como energía del Nej Uma Nej Tay (Dioses Luna y Sol) creadores del universo nasa."

Como se ve, el "formalismo" tiene sus límites: Aunque el ritual se basa en una estructura tetraléctica; no obstante, se refiere a los nueve guardianes y los siete arcos de la naturaleza, cada ciclo del ritual implica una quinta mambeada y el ritual de limpieza sigue hasta que el cielo se despeje y el $p t a^{\prime} z$ (la enfermedad) se desaparezca.

Según Descola (2012), las "ontologías analógicas" con sus rasgos característicos de una organización del mundo en paridades, están difundidas no tan sólo en el mundo andino, sino también en Mesoamérica y en China, y este sistema de clasificación era característico para la Europa de la época del Renacimiento, como ha demostrado Foucault (1968) en su obra célebre "Las palabras y las cosas". En el futuro faltan estudios detallados que analicen las diferencias minuciosas entre estas ontologías analógicas del mundo, relacionándolas con los factores de la historia, de la organización social, el modo de producción, y las relaciones de poder, de este modo "purgando" el posestructuralismo de sus deficiencias que consisten en ignorar las bases concretas de la existencia humana.

\footnotetext{
${ }^{7}$ El médico tradicional toma la jigra (mochila) junto con la chonta con su mano izquierda, pero utilizando la mano derecha dirige la anterior, para darle la vuelta sobre el participante desde el pie derecho, pasando por la cabeza, hasta el pie izquierdo. Este recorrido cultural se refiere a la diferenciación horizontal del cosmos nasa - la enfermedad (el sucio) tiene que salir hacia la parte izquierda del cuerpo humano. Después de terminar el giro ("volteo"), él sopla fuerte hacia la izquierda (compare Portela 2002).
} 


\section{AGRADICIMIENTOS}

El presente trabajo fue patrocinado por el Proyecto Prometeo de la Secretaría de Educación Superior, Ciencia, Tecnología e Innovación de la República del Ecuador.

\section{BIBLIOGRAFÍA}

Achig Balarezo, D., 2010. El Lenguaje de la Medicina China y el Comportamiento. Cuenca: Abril Ediciones.

Bataille, G., 1974: Théorie de la religion. Paris: Collection Tel (ํ102), Gallimard.

Baumann, M.-P., 1994. Das ira-arka-Prinzip im symbolischen Dualismus andinen Denkens. En Baumann, M.-P. (Ed.). Kosmos der Anden: Weltbild und Symbolik indianischer Tradition in Südamerika, pp. 274 -316, München: Diederich Verlag.

Bernal Villa, S.E., 1954. Medicina y magia entre los paeces. Revista Colombiana de Antropología, 2 , 219-264.

Bettin, I.,1994. Weltbild und Denken in den Zentral-Anden. En Baumann, M.-P. (Ed.). Kosmos der Anden, Weltbild und Symbolik indianischer Tradition in Südamerika, pp. 14-39. München: Diederich Verlag.

Bird-David, N., 1999. Animism' revisited, personhood, environment and relational epistemology. Current Anthropology, 40 (Supplement), 67-91.

Caillois, R., 1950. L’homme et le sacré. Paris: Collection Folio essais (N84), Gallimard.

Deleuze, G., F. Guattari, 2004. Mil Mesetas. Capitalismo y esquizofrenia. Valencia: PRE-TEXTOS.

Descola, P., 2012. Más allá de naturaleza y cultura. Buenos Aires: Amorrortu Editores, 624 pp.

Drexler, J., 2007. Las "siembras de agua": La concepción y las prácticas de salud territorial de los nasa (páez) de Tierra dentro en Colombia - Otra mirada indígena a la reforestación. Revista Antropológicas, 18(1), 137-170.

Drexler, J., 2012. Das linke Heilige und die Gewalt. Transgression, Subversion und Normativität in indioamerikanischer und heterologischer Perspektive Batailles. In Riekenberg, M. (Ed.). Zur Gewaltsoziologie von Georges Bataille, pp. 51-71. Leipzig: Leipziger Universitätsverlag.

Durkheim, É., M. Mauss, 1903. De quelques formes de classification - contribution à l'étude des représentations collectives. Année Sociologique, 6, 1-72. Disponible en

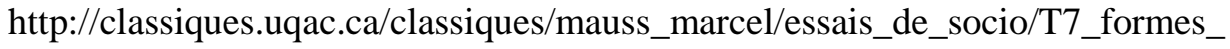
classification/formes_classification.html.

Earls, J., I. Silverblatt, 1978. La realidad física y social en la cosmología andina. Actes du XLII Congrès International des Américanistes, Vol. IV, 299-326, Paris.

Faust, F.X., 1994. Cultura: un caos determinado por sus fractales. I Fogli di ORISS, 1-2, 9-29.

Faust, F.X. 1996. Un préstamo de la geometría fractal para la descripción de culturas emparentadas: Lo que hace las culturas amerindias similares entre ellas. Thule: Revista Italiana de Studi Americanistici, 1, 133-55.

Foucault, M. 1967. Humanismo implica fofería. Michel Foucault entrevistado por Paolo Caruso. Disponible en http://www.contranatura.org/articulos/Filos/Foucault-Humanismo.htm.

Foucault, M. 1968. Las palabras y las cosas. Una arqueología de las ciencias humanas. Buenos Aires: Siglo XXI Editores.

Godelier, M., 1989. Lo ideal y lo material. Pensamiento, economías, sociedades. Madrid: Taurus, $308 \mathrm{pp}$.

Godelier, M., 1998. El enigma del don. Barcelona/Buenos Aires/México: Paidós Básica, 315 pp.

Gómez Valencia, H., 2000. De la justicia y el poder indígena. Popayán: Editorial Universidad del Cauca. 
Halbmayer, E., 2012. Amerindian mereology: Animism, analogy, and the multiverse. INDIANA, 29, 103-125.

Hertz, R., 1973. The pre-eminence of the right hand: A study in religious polarity. En: Needham, R. (Ed.): Right and Left: Essays on Dual Symbolic Classification. Chicago/London: University of Chicago Press, pp. 3-31.

Ingold, T., 2006. Rethinking the animate, re-animating thought. Ethnos: Journal of Anthropology 71(1), 9-20.

Lajo, J., 2002. QHÁPAQ KUNA. Más alla de la civilización. Reflexiones sobre la filosofía occidental y la sabiduría indígena. 26 pp. Disponible en http://emanzipationhumanum.de/downloads/ Capac-Cuna.pdf.

Lajo, J., 2006. QHAPAQ ÑAN. La Ruta Inka de Sabiduría. Quito: Ediciones Abya-Yala, 196 pp. Disponible en https://repository.unm.edu/bitstream/handle/1928/12589/ Qhapaq\%20\%C3\%91an\%201a\%20ruta\%20inka\%20de\%20sabidur\%C3\%ADa.pdf?sequence=1.

Latour, B., 1991. Nous n'avons jamais été modernes: Essay d'anthropologie symétrique. Paris: Collection: La Découverte Poche/Sciences humaines et sociales, $\mathrm{N}^{\circ} 26,210 \mathrm{pp}$.

Lévi-Strauss, C., 1962. El pensamiento salvaje. México: Fondo de Cultura Económica (FCE), 416 pp.

Lozada, B., 2006. Cosmovisión, historia y política en los Andes. Cuarte Parte: §16, pp. 228-241. Bolivia, La Paz: Producciones CIMA.

Mauss, M., 1925. Essai sur le don. Forme et raison de l'echange dans les sociétés archaiques, L'Année sociologique, Nueva serie, 1.

Métraux, A., 1949. Religion and Shamanism. In: Handbook of South American Indians, 5, 559-599. Washington DC: Smithsonian Institute.

Münzel, M., 1985. Die Indianer, Band 2: Mittel- und Südamerika. München: dtv, 331 pp.

Painiqueo, M., s.f. Filosofía Indianista. Documento de la Comunidad Mapuche Aonikenk, Chubut Argentina. Disponible en http://www.elchenque.com.ar/aoni/filo/filosofia.htm.

Pineda Virgilio, R., 2005. Los sabios y grandiosos fundamentos de la indianidad. Disponible en http://www.archivochile.com/Pueblos_originarios/cultura_tradi/POcultradi0008.pdf, 12 pp.

Portela, Guarín, H. 2002: Cultura de la salud páez: Un saber que perdura, para perdurar. Popayán: Editorial Universidad del Cauca.

Reichel-Dolmatoff, G., 1986. Desana: Simbolismo de los indios Tukano del Vaupés. Bogotá: Procultura, 2a ed., $350 \mathrm{pp}$.

Roe, P., 1982. The Cosmic Zygote: Cosmology in the Amazon Basin. New Brunswick, New Jersey: Rutgers University Press, 416 pp. Disponible en http://udel.edu/ roe/TheCosmicZygote/ fulltext.pdf.

Spradley, J., 1980. Participant Observation. New York: Holt, Rinehart and Winston, 247 pp.

Spittler, G., 2001. Teilnehmende Beobachtung als Dichte Teilnahme. Zeitschrift für Ethnologie, 126, (H.1), 1-26, Berlin: Reimer Verlag.

Sullivan, L.E., 1987. Icanchu's Drum. An orientation to meaning in South American religions. New York: Macmillan Co., 1003 pp.

Taussig, M.T., 2010. The devil and commodity fetishism in South America, Chapel Hill: The University of North Carolina Press, 315 pp. Disponible en http://www.wkvstuttgart.de/uploads/media/taussig_devil_commodity.pdf.

Viveiros de Castro, E., 1998. Cosmological deixis and Amerindian perspectivism. Journal of the Royal Anthropological Institute, N.S., 4, 469-88.

Wolf, E.R., 1999. Envisioning power. Ideologies of dominance and crisis. Berkeley/Los Angeles/ London: University of California Press.

Yampara Huarachi, S., 2011. Cosmovivencia Andina. Vivir y convivir en armonía integral - Suma Qamaña. Bolivian Studies Journal /Revista de Estudios Bolivianos, 18, 1-22.

Zerries, O., 1954. Wild- und Buschgeister in Südamerika. Wiesbaden: Franz Steiner Verlag, 282 pp. 
MASKANA, Vol. 6, No. 2, 2015

Zhou, X-S., 2007. Chinese medicine study guide: Fundamentals. Beijing: People's Medical Publishing House, 360 pp. 